\title{
Possible asynchronous parturition in a multifetal strepsirrhine: Hapalemur meridionalis
}

\author{
T.M. Eppley ${ }^{1,2,3,4}$, G. Donati ${ }^{3}$, J.U. Ganzhorn ${ }^{2}$ \\ ${ }^{1}$ Department of Anthropology, University of Texas at Austin, Austin, USA. \\ ${ }^{2}$ Biozentrum Grindel, Department of Animal Ecology and Conservation, University of Hamburg, Hamburg, Germany. \\ ${ }^{3}$ Nocturnal Primate Research Group, Department of Social Sciences, Oxford, United Kingdom.
}

\begin{abstract}
Although infrequent among primates, twinning is common among strepsirrhines, a group of primates that includes the lemurs of Madagascar. As with any multifetal pregnancy, complications during gestation or even parturition can arise due to various factors (e.g., amniotic infection, stress). On rare occasions during labour of twins, parturition may be delayed between the two neonates, a phenomenon known as 'delayed interval delivery' that has been well-documented among the human medical journals. Based on circumstantial evidence, we report an opportunistic account of a habituated, adult female southern bamboo lemur (Hapalemur meridionalis) from Mandena, southeast Madagascar, first giving birth to an infant in midOctober 2013 (found deceased), and then birthing a live infant sometime between 5-21 days later. Similar to cases reported in human medical literature, the second infant survived and appeared to stay healthy until the conclusion of the study. Our account of asynchronous parturition of twins in a non-human primate is, to our knowledge, the first reported case in the literature.
\end{abstract}

Keywords: delayed interval delivery, pregnancy, southern bamboo lemur, twinning.

\section{Introduction}

The asynchronous delivery of human twins was first described as a coincidental event by Carson (1880) with 44 days occurring between births. Since then, the occurrence of this phenomenon (i.e., contractions cease between multifetal births) has been well documented within the human medical literature (reviewed in Wittmann et al., 1992) where it is more commonly referred to as 'delayed interval delivery.' The majority of this literature is composed of reports and small case studies that describe proactive management policies of intentionally delaying delivery after preterm parturition of a first twin; however, not all delayed interval deliveries are medically-inhibited by tocolytics, i.e., a labour suppressant medication (Wittmann et al., 1992). Whether natural or medically-inhibited, the cessation of labour after the delivery of a premature first twin has been demonstrated to show an improved fetal outcome for the second twin (Song et al., 2000; Wouters et al.,
2009). According to a human population-based study, asynchronous parturition occurred in approximately $0.09 \%$ of multifetal pregnancies; however, it was not disclosed how many of these delays were due to human medical intervention (Zhang et al., 2004). To our knowledge the asynchronous birthing of twins has never been described in any non-human primates.

For this phenomenon to occur, the twins must be dizygotic. In short, dizygotic twins develop from two separate ova in the uterus, with each zygote developing its own amnion (i.e., amniotic sac) and chorion as part of two separate placentas. Placentas do not necessarily need to be un-fused for this phenomenon to occur, as among humans a fused placenta from the first twin can remain in-utero until the birth of the second (de Jong et al., 1995). Dizygotic twinning is much more common than monozygotic twinning in humans (Hoekstra et al., 2008) and is known to occur in other non-human primates (Geissmann, 1990; Ely et al., 2006; Harris et $a l ., 2014)$. Twinning rates among haplorrhine primates are low (e.g., Geissmann, 1990; Link et al., 2006; Huck et al., 2014; but see Bales et al., 2001 for an example of callitrichid twinning), however, it appears to be extremely common in primates with a bicornuate uterus, such as in Strepsirrhini, i.e., a suborder of Primates which includes lemurs, lorises, and galagos (Pasztor and van Horn, 1976; van Horn and Eaton, 1979; Benirschke and Miller, 1982; Parga and Lessnau, 2005; Tecot et al., 2013).

In this report we present the first observation of a multifetal non-human primate delivering one offspring, and then giving birth to a second infant multiple days later.

\section{Materials and Methods}

We conducted observations on four social groups of southern bamboo lemurs (Hapalemur meridionalis) from October 2012 through December

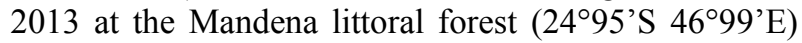
in southeast Madagascar. This protected area is located approximately $10 \mathrm{~km}$ north of Fort-Dauphin and is 230 ha of degraded littoral forest fragments and interspersed swamp (Eppley et al., 2015a). These relatively smallbodied primates (mean $\pm \mathrm{SD}$ weight across sexes from wild: $1.072 \pm 0.107 \mathrm{~kg} ; \mathrm{n}=15$; Eppley et al., 2015c) are characterized by folivory and exhibit a cathemeral

${ }^{4}$ Corresponding author: eppleyti@gmail.com

Phone: +01(512) 800-02694

Received: September 21, 2015

Accepted: February 1, de 2016 
activity pattern (Eppley et al., 2011, 2015b). They live in small social groups with one or two breeding females and typically one breeding male, with an average group size of $5.6 \pm 1.5$ individuals ( $\mathrm{n}=5$; Eppley et al., 2016).

As part of a larger behavioural ecology research project, ten adult $H$. meridionalis, from across four neighbouring social groups, were captured and collared by an experienced Malagasy technician using a blowpipe and lightweight syringes (Telinject, USA) with a hypnotic anaesthesia $4 \mathrm{mg} / \mathrm{kg}$ of ketamine hydrochloride) between October and December 2012. Individuals were fitted with an external radiotransmitter (ARC400, Advanced Telemetry Systems, Isanti, MN, USA) with individual identification tags to assist in the initial habituation and in decreasing the amount of time it takes to locate the focal group each morning. Details of the capture protocol followed have been previously described in Eppley et al. (2015b), and collars were removed at the end of the study in December 2013 following the same protocol.

Focal data collection was limited to three $H$. meridionalis groups that resulted in approximately 50 $\mathrm{h} /$ month of data from full-day focal follows, providing an approximate total of $150 \mathrm{~h} /$ month. For the sake of this report, we will only describe the events that occurred while following one of these groups (M1) as collected ad libitum, between October and November 2013. Hapalemur live in stable social units (Tan, 2006); at the time of these observations, group M1 comprised one adult female (M1F2), one adult male (M1M2), and one juvenile female (M1F4) who was $\leq 1$ year old.

This research was carried out under the Accord de Collaboration between the University of Antananarivo and the University of Hamburg. Research protocols were approved and permits authorized by Commission Tripartite of the Direction des Eaux et Forêts de Madagascar (Autorisation de recherché $\mathrm{N}^{\circ}$ 240/12/MEF/SG/DGF/DCB.SAP/SCB du 17/09/2012), adhering to the legal requirements of Madagascar.

\section{Results}

We conducted a full-day follow (sunrise to sunset: 05:30 - 18:15) of the $H$. meridionalis group M1 on October 17, 2013 and all three individuals were present. Upon locating the M1 group in the center of their territorial home range at 08:00 on October 18, 2013, we first found the adult female (M1F2) sitting on a tree branch approximately three and a half meters high and looking at the ground. We discovered a neonate positioned ventrally on the forest floor nearby. The male infant, $42 \mathrm{~g}$, was without a heart rate and it appeared rigor mortis had set in as the limbs remained rigid when handling the corpse. The body was for the most part dry and we were unable to locate the placenta. The two other individuals from the group were not in the immediate vicinity but were located in a sleeping huddle $30 \mathrm{~m}$ away. The dead neonate did not show any signs of wounding or aggression, but did exhibit a lack of fur on its ventral side and near hairless tail, in addition to peculiar small red bumps on the chest. Over the next four consecutive days, we conducted full-day follows with this group and can conclusively state that there were only three individuals within the M1 group during this time. On November 20th, we resumed our focal data collection with M1 group and found the adult female M1F2 now with an infant. This leads us to conclude that the sole adult female in the group was multifetal and that at some point between October 23rd and November 20th delivered a second, full-term neonate. At the conclusion of the study in early January 2014, the second infant was still alive and appeared in good health.

\section{Discussion}

To our knowledge, this is likely the first reported case of a natural delayed interval (asynchronous) parturition to occur in a non-human primate. It has been reported that twinning is common among $H$. alaotrensis, a close congener of $H$. meridionalis (Steyn and Feistner, 1994; Beattie and Feistner, 1998; Mutschler et al., 2000), and while it is less frequent among $\mathrm{H}$. griseus (Haring and Davis, 1998), twinning is known to occur (Tan, 2000). Although lemurs are known for their high-frequency of multifetal pregnancies similar to some callitrichid primates (Bales et al., 2001; Harris et al., 2014), these also result in high infant mortality (Debyser, 1995; Parga and Lessnau, 2005; Volampeno et al., 2011). In some cases an accidental fall may cause or lead to death in a neonate (Morland, 1990), yet stillborn and infant mortality have been shown to increase with multifetal births, often with stress and infections linked to infant/juvenile mortality (Debyser, 1995). In our observation, the first neonate lacked ventral fur and had a near hairless tail, suggesting that it was delivered prematurely (Cummings et al., 2012). In any case, the occurrence of a delayed interval birth is exceedingly rare.

Most lemurs are sexually quiescent throughout much of the year and exhibit a strict seasonal breeding once per year, an adaptation resulting in mono-estrus and a short estrus period (Jolly, 1967; Rasmussen, 1985; Brockman and van Schaik, 2005). With an interbirth interval of one year, the same is true of Hapalemur spp. (Tan, 2000, 2006); however, the degree of seasonal stringency may be affected by resource abundance (Mutschler et al., 2000; Brockman and van Schaik, 2005). Similar to reports that $H$. griseus mates in JuneJuly and gives birth in October-November (Tan, 2000), all adult female $H$. meridionalis within these neighbouring groups were first observed with infants from mid-November to mid-December (Table 1), making it likely that the dead neonate was in fact premature. 
Eppley et al. Asynchronous twinning in a lemur.

Table 1. Date of first observations of H. meridionalis infants in Mandena and their presumed mothers in 2013.

\begin{tabular}{lccl}
\hline Date (of first sight) & Group & Mother ID & \multicolumn{1}{c}{ Outcome } \\
\hline October 18 & 1 & M1F2 & Died - likely premature stillbirth \\
November 15 & 2 & M2F1 & Alive through January 2014 \\
November 19 & 4 & M4F1 & Died - unknown cause \\
November 20 & 1 & M1F2 & Alive through January 2014 \\
December 14 & 4 & M4F2 & Alive through January 2014 \\
\hline
\end{tabular}

Note: These were the only adult $H$. meridionalis females in our focal groups.

While we cannot conclusively state that both infants were birthed by M1F2 due to lack of genetic samples, strong evidence supports our assertion. First, the adult female M1F2 was noticeably larger preceding the discovery of the dead neonate in October and infant in November. Second, Hapalemur spp. are highly territorial and protect their territory via agonistic encounters with neighbouring bamboo lemur groups (Nievergelt et al., 1998; Tan, 2006). Similar to congeners, $H$. meridionalis in Mandena maintain minimal home range overlap between groups (Eppley et al., 2015a), leading groups to rarely come within visual distance of others. Due to this, $H$. meridionalis exhibit extremely low rates of inter-group agonism in Mandena (Eppley et al., 2016). Furthermore, the site of the dead neonate was in the central core area of group M1's territory, a relatively large distance (approximately 150 $\mathrm{m}$ ) from the shared borders with neighbouring groups. Thus, it seems unlikely that an out-group adult female would travel to the center of another group's territory to give birth. Third, though infanticide has been observed among some lemur species (reviewed in Tecot et al., 2013), the dead neonate showed no signs of wounding or aggression, therefore making it unlikely that the infant was killed by its own or a neighbouring group.

Our report being an observation among wild primates leaves us in a difficult position to speculate the circumstances surrounding how and why this occurred. It is possible that the cost of enduring a multifetal pregnancy could be too great if certain resources are not as abundant. Numerous health issues can arise from a multifetal gestation, placing morbidity or mortality risks on the fetuses and mother (Kalchbrenner et al., 1998). It is possible that preterm infection (potentially indicated by the observed red bumps across the neonate ventrum) could have been responsible for the infant's death (Darmstadt et al., 2000), whether stillborn or shortly after birth. The offspring of primate mothers who experienced prenatal stress may have delayed motor activity or other long-term morbidities as a result (Schneider et al., 1999; Mulder et al., 2002). Premature birth may result in an increased risk of both short- and long-term developmental neurological, pulmonary, and visual dysfunctions (Dammann et al., 2005) thus it is likely that the second fetus benefitted from increased time in the womb, potentially accounting for its survival. When multifetal pregnancies are complicated by the immature birth of one fetus, delayed interval delivery may offer a greater survival chance and favourable outcome for the remaining fetuses (de Jong et al., 1995; Kalchebrenner et al., 1998; Zhang et al., 2004; Arabin and van Eyke, 2009).

Our account of asynchronous parturition of twins in a non-human primate is to our knowledge the first reported case in the literature. Though circumstantial, it seems that this phenomenon may be a potential adaptive reproductive strategy, benefitting the health of the delayed neonate and ensuring successful reproductive effort of the mother in both human and non-human primates.

\section{Acknowledgments}

This study was conducted under the Accord de Collaboration between the University of Antananarivo and the University of Hamburg. We thank the Direction du Système des Aires Protégées, and the Ministère de l'Environnement et Forêts of Madagascar for permission to conduct research. In addition, we thank Jacques Rakotondranary and Tolona Andrianasolo for their logistical assistance and obtaining research permits. Funding provided by the American Society of Primatologists, Conservation International's Primate Action Fund, IDEAWILD, Mohamed bin Zayed Species Conservation Fund (Project Number: 11253008), Primate Conservation Inc., Primate Society of Great Britain/Knowsley Safari Park. We greatly appreciate the assistance and logistical support provided by the Biodiversity team at Rio Tinto QMM, especially JeanBaptiste Ramanamanjato, Johny Rabenantoandro, Faly Randriatafika, Laza Andriamandimbiarisoa, and David Rabehevitra, and to Robertin Ravelomanantsoa for his assistance in the field. Special thanks to Sue L. Hall, M.D., Katie Hall, and John Gramieri for insightful discussions.

\section{References}

Arabin B, van Eyck J. 2009. Delayed-interval delivery in twin and triplet pregnancies: 17 years of experience in 1 perinatal center. Am J Obstet Gynecol, 200:154.e1154.e8.

Bales K, O'Herron M, Baker AJ, Dietz JM. 2001. Sources of variability in numbers of live births in wild golden lion tamarins (Leontopithecus rosalia). Am J Primatol, 54:211-221. 
Beattie JC, Feistner ATC. 1998. Husbandry and breeding of the Alaotran gentle lemur Hapalemur griseus alaotrensis at Jersey Wildlife Preservation Trust. Int Zoo Yearb, 36:11-19.

Benirschke K, Miller CJ. 1982. Anatomical and functional differences in the placenta of primates. Biol Reprod, 26:29-53.

Brockman DK, van Schaik CP. 2005. Seasonality and reproductive function. In: Brockman DK, van Schaik CP (Ed.). Seasonality in Primates: studies of living and extinct human and nonhuman primates. Cambridge, UK: Cambridge University Press. pp. 269-305.

Carson JL. 1880. Twins born with an interval of 44 days. Br Med J, 1:242.

Cummings JR, Muchlinski MN, Kirk EC, Rehorek SJ, DeLeon VB, Smith TD. 2012. Eye size at birth in prosimian primates: life history correlates and growth patterns. PLoS ONE, 7:e36097.

Dammann O, Leviton A, Gappa M, Dammann CE. 2005. Lung and brain damage in preterm newborns, and their association with gestational age, prematurity subgroup, infection/inflammation and long term outcome. BJOG (Int J Obstet Gynecol), 112 (suppl.1):4-9.

Darmstadt GL, Dinulos JG, Miller Z. 2000. Congenital cutaneous candidiasis: clinical presentation, pathogenesis, and management guidelines. Pediatrics, 105:438-444.

Debyser IWJ. 1995. Prosimian juvenile mortality in zoos and primate centers. Int J Primatol, 16:889-907.

de Jong MW, Pinas IM, van Eijck J. 1995. Delayed interval delivery after intrauterine infection and immature birth of twin 1 - a case report and literature review. Eur J Obstet Gynecol R B, 63:91-94.

Ely JJ, Frels WI, Howell S, Izard MK, Keeling ME, Lee RD. 2006. Twinning and heteropaternity in chimpanzees (Pan troglodytes). Am J Phys Anthropol, 130:96-102.

Eppley TM, Verjans E, Donati G. 2011. Coping with low-quality diets: a first account of the feeding ecology of the southern gentle lemur, Hapalemur meridionalis, in the Mandena littoral forest, southeast Madagascar. Primates, 52:7-13.

Eppley TM, Donati G, Ramanamanjato J-B, Randriatafika F, Andriamandimbiarisoa LN, Rabehevitra D, Ravelomanantsoa R, Ganzhorn JU. 2015a. The use of an invasive species habitat by a small folivorous primate: implications for conservation. PLoS ONE, 10:e0140981.

Eppley TM, Ganzhorn JU, Donati G. 2015 b. Cathemerality in a small, folivorous primate: proximate control of diel activity in Hapalemur meridionalis. Behav Ecol Sociobiol, 69:991-1002.

Eppley TM, Hall K, Donati G, Ganzhorn JU. 2015c. An unusual case of affiliative association of a female Lemur catta in a Hapalemur meridionalis social group. Behaviour, 152:1041-1061.

Eppley TM, Ganzhorn JU, Donati G. 2016. Latrine behaviour as a multimodal communicatory signal station in wild lemurs: the case of Hapalemur meridionalis. Anim Behav, 111:57-67.

Geissmann T. 1990. Twinning frequency in catarrhine primates. J Hum Evol, 5:387-396.

Haring D, Davis K. 1998. Management of the grey gentle or Eastern lesser bamboo lemur Hapalemur griseus griseus at Duke University Primate Center, Durham. Int Zoo Yearb, 36:20-34.

Harris RA, Tardif SD, Vinar T, Wildman DE, Rutherford JN, Rogers J, Worley KC, Aagaard KM. 2014. Evolutionary genetics and implications of small size and twinning in callitrichine primates. Proc Natl Acad Sci USA, 111:1467-1472.

Hoekstra C, Zhao ZZ, Lambalk CB, Willemsen G, Martin NG, Boomsma DI, Montgomery GW. 2008. Dizygotic twinning. Hum Reprod Update, 14:37-47.

Huck M, van Lunenburg M, Dávalos V, Rotundo M, Di Fiore A, Fernandez-Duque E. 2014. Double effort: Parental behavior of wild Azara's owl monkeys in the face of twins. Am J Primatol, 76:629-639.

Jolly A. 1967. Breeding synchrony in wild Lemur catta. In: Altmann SA (Ed.). Social Communication among Primates. Chicago, USA: University of Chicago Press. pp. 3-14.

Kalchbrenner MA, Weisenborn EJ, Chyu JK, Kaufman HK, Losure TA. 1998. Delayed delivery of multiple gestations: maternal and neonatal outcomes. Am J Obstet Gynecol, 179:1145-1149.

Link A, Palma AC, Velez A, de Luna AG. 2006. Costs of twins in free-ranging white-bellied spider monkeys (Ateles belzebuth belzebuth) at Tinigua National Park, Colombia. Primates, 47:131-139.

Morland HS. 1990. Parental behavior and infant development in ruffed lemurs (Varecia variegata) in a Northeast Madagascar rain forest. Am J Primatol, 20:253-265.

Mulder EJH, Robles de Medina PG, Huizink AC, Van den Bergh BRH, Buitelaar JK, Visser GHA. 2002. Prenatal maternal stress: effects on pregnancy and the (unborn) child. Early Hum Dev, 70:3-14.

Mutschler T, Nievergelt CM, Feistner ATC. 2000. Social organization of the Alaotran gentle lemur (Hapalemur griseus alaotrensis). Am J Primatol, 50:924.

Nievergelt CM, Mutschler T, Feistner ATC. 1998. Group encounters and territoriality in wild Alaotran gentle lemur (Hapalemur griseus alaotrensis). Am J Primatol, 46:251-258.

Parga JA, Lessnau RG. 2005. Female age-specific reproductive rates, birth seasonality, and infant mortality of ring-tailed lemurs on St. Catherines Island: 17-year reproductive history of a free-ranging colony. Zoo Biol, 24:295-309.

Pasztor LM, van Horn RN. 1976. Twinning in prosimians. J Hum Evol, 5:333-337.

Rasmussen D. 1985. A comparative study of breeding seasonality and litter size in eleven taxa of captive lemurs (Lemur and Varecia). Int J Primatol, 6:501-517. 
Schneider ML, Roughton EC, Koehler AJ, Lubach GR. 1999. Growth development following prenatal stress exposure in primates: an examination of ontogenetic vulnerability. Child Dev, 70:263-74.

Song T-B, Jeong J, Kim Y-H, Kim E-K. 2000. Delayed interval delivery in multiple gestations. Arch Gynecol Obstet, 263:185-187.

Steyn H, Feistner ATC. 1994. Development of a captive-bred infant Alaotran gentle lemur Hapalemur grieseus alaotrensis. Dodo, 30:41-51.

Tan CL. 2000. Behavior and ecology of three sympatric bamboo lemur species (genus Hapalemur) in Ranomafana National Park, Madagascar. Stony Brook, NY: State University of New York. PhD dissertation.

Tan CL. 2006. Behavior and ecology of gentle lemurs (genus Hapalemur). In: Gould L, Sauther M (Ed.). Lemurs: ecology and adaptation. New York, USA: Springer. pp. 369-381.

Tecot SR, Baden AL, Romine N, Kamilar JM. 2013. Reproductive strategies and infant care in the Malagasy primates. In: Clancy KBH, Hinde K, Rutherford JN
(Ed.). Building Babies. New York, USA: Springer. pp. 321-359.

van Horn R, Eaton GG. 1979. Reproductive physiology and behavior in prosimians. In: Doyle G, Martin RD (Ed.). The Study of Prosimian Behavior. New York, USA: Academic Press. pp. 79-122.

Volampeno MSN, Masters JC, Downs CT. 2011. Life history traits, maternal behavior and infant development of blue-eyed black lemurs (Eulemur flavifrons). Am J Primatol, 73:1-11.

Wittmann BK, Farquharson D, Wong GP, Baldwin V, Wadsworth LD, Elit L. 1992. Delayed delivery of second twin: report of four cases and review of the literature. Obstet Gynecol, 79:260-263.

Wouters KA, Gianotten J, Bayram N, Doornbos JPR. 2009. Term life birth after late abortion of the first twin. Acta Obstet Gynecol Scand, 88:1148-1152.

Zhang J, Hamilton B, Martin J, Trumble A. 2004. Delayed interval delivery and infant survival: a population-based study. Am J Obstet Gynecol, 191:470476. 